\title{
Academic psychiatry in Russia: new times, new challenges
}

\author{
Molecular Psychiatry (2004) 9, 975-976. doi:10.1038/ \\ sj.mp.4001603
}

My introduction to academic psychiatry began in the fall of 1982, when I arrived at the newly organized Mental Health Research Center (MHRC) as a graduate student in the Genetics Department of Moscow State University. My goal was clear: I aspired to find something unusual in human DNA to explain mental illness. What was found first, however, was that I needed to master the field of carpentry. As a prelude to DNA study, laboratory benches were made from pieces of multicolor Finnish furniture. The electrophoresis DNA sequencing apparatuses were constructed using glass shelves that come with the furniture (they appeared to be excellently suited for use as thermostable gel plates). In an unpredicted twist, my early experiments in the MHRC led to the finding of hypervariable DNA stretches (and, predictably, the first $\mathrm{PhD}$ theses describing DNA typing in forensic science). Fortunately, no concern was raised at the time as to how relevant these findings were to psychiatric illness. It is now clear that the use of these types of DNA (mini/microsatellite markers) paved the path to gene hunting for many human diseases, including Alzheimer's.

The establishment of the All-Union Mental Health Research Center of the Academy of Medical Sciences in 1981 was a milestone in the development of academic research psychiatry in the USSR/Russia. The MHRC grew from the Institute of Psychiatry, organized in 1944. In its infancy, the Institute played a leading role in the development of theoretical and clinical practices, coupled with other important initiatives, for example, the prohibition of prefrontal lobotomy in the USSR. The essence of the mission of the MHRC was to create multidisciplinary research that integrated clinical and biological psychiatry. Thanks to great enthusiasm of one of the founders of the MHRC (biological psychiatrist ME Vartanyan) new frontiers in molecular research were encouraged. There was one delicate circumstance at the time. Soviet clinical psychiatry was not welcome in the West. Cooperation in basic research might help to overcome the tension. Collaborations in neurosciences, participation in international conferences, schools and professional meetings (eg USSR-USA meeting in psychiatric genetics in Moscow) were initiated in late 1980s with the hope of integrating Russian scientists into the international community.

The MHRC, now under the leadership of clinical psychiatrist AC Tiganov, is at present a large, complex institution that encompasses 11 clinical departments and 13 research laboratories. The labs perform studies ranging from patho- and neuromorphological, to biochemical, immunological and molecular-genetics. Clinical psychopharmacology, within the clinical division of the Center, is well developed. These clinical departments are often integrated with municipal mental hospitals and outpatient psychiatric centers, and address all psychiatric illness. Traditionally, Alzheimer's disease or senile dementias are in the domain of psychiatric, rather neurological, institutions in Russia. Work in the field of Alzheimer's disease in Russia has, in fact, a long history. It began with the early work on psychiatric diseases of late age and dementia by EY Sternberg, who emigrated from Nazi Germany to Russia in the 1930s. Recent research on Alzheimer's disease exemplifies strongly the extent of international cooperation and collaboration between the molecular-genetic and clinical groups nationally and internationally.

In a new Russia, the role of psychiatry in society is regulated by the law of 'the Russian Federation on Psychiatric care and the safeguarding of citizen's right in the dispensing of such care' accepted on July 2, 1992. During this critical reform, attention was paid to the development of a nonhospital form of psychiatric service. Psychiatry became more 'open'. Interactions with the public were made; these connections even included religious organizations. The increasing involvement of the Orthodox Church is evident. The definition of 'sin' as a causative factor for mental disorder (once I found the phrase 'somatization of sin' for psychosomatic disorders) may or may not challenge some biological concepts, but in rehabilitation programs, the efforts of the church and psychiatrists seems not to be contradictory. It is worth noting in this regard that priests participating in this practice are often former medical doctors in psychiatry.

The international standards (eg ICD-10 versions translated in Russian) are now accepted in Russian psychiatry. However, research publications in international journals, particularly in those journals, which are clinically oriented, are not yet common.

The difficulties of conducting psychiatric research in Russia are obvious. The state support to institutions was drastically reduced. The low salaries paid to researchers and medical personal do not cover the costs of minimal living standards. Thus, similarly to their US colleagues, the principal investigators are on their own to search for support from external resources. Not too many sources are available. Private foundation funds are not yet developed, although I 
am aware of some single cases of donations from Russian billionaires or companies to geriatric research. There is no competitive grant system in medicine comparable to NIH, for example. A positive sign is the establishment of the Russian Fund for Basic Research (RFBR), which among basic sciences supports nonclinically oriented medical research. There are also a few international foundations such as INTAS (EU), CRDF (US) and NIH FIRCA granting joint projects of Russian and European or US collaborative groups. The Howard Hughes Medical Institute directly finances research in Russia through a highly competitive granting system for Eastern Europe and Former Soviet Union countries. The Stanley Medical Research Institute continues to provide support for research in schizophrenia and affected disorders in Russia. This support equates only to a few drops of water from an entire sea, and it is questionable whether a true national program in mental health in Russia has emerged.

There are other important factors at play. In the early 1990s, the people of Russia found themselves living in another country and under a new government's experiment called economical 'shock therapy' (a term not unfamiliar to psychiatrists). The demographic results of this experiment were as quick as they were shocking. The mortality in population and the gap in life expectancy between men and women achieved unprecedented levels in the modern world (57.7 for men and 71.2 for women in 1994). Some recovery (the average ages rising to 61.44 for men and 73.24 for women in 1998) was documented. This might be perceived as a sign of adjustment of a new society to the new conditions, but then a new economical default in 1998 reversed the positive dynamic. Stress is argued as the primary causative factor of such negative outcomes. Behavior-related patterns (anxiety, depression and aggression) seemed to correlate better with the mortality statistics than poverty alone. The major cause of mortality was shown to be more directly related to cardiovascular disorders (quoting soviet neuropsychologist AR Luria: 'The brain cries-but the tears are in the stomach, heart, liver...'). Of concern, the second cause of mortality in men (and third in women) is violent death. Suicide was a main contributor to violent death in both men and women, rising from 47.7 (men) and 11.2 (women) in 1991 to 76.9 (men) and 13.6 (women) in 1994 per 100000 population. The longterm consequences of chronic psychological stress in a society that is radically reconstructed is hardly predictable. Socially oriented prospective studies are emerging in academic psychiatry. Alcoholism, growing drug abuse problems and post-traumatic war syndromes are challenges in Russia.

It would be difficult to count the number of studies in biological psychiatry and neuroscience that are dispersed through various Russian institutions. There are however no more one or two institutions seriously working on molecular-genetic mechanisms for mental diseases or Alzheimer's disease. This is not enough for such a large country. Traditional academic research is concentrated in Moscow and St Petersburg and, to some extent, in the Siberian branches of the Russian Academy of Sciences and Academy of Medical Sciences. Annual International conferences of Biological Psychiatry (focused on stress and behavior) and Meetings of Psychiatrists of Russia are systematic events that serve an important function in uniting the Russian research community from different fields of academic psychiatry.

Another key variable in academic life in Russia is the 'brain drain', which was particularly evident in laboratory-oriented research in the first half of 1990s. A positive factor is that the quality of the educational system in Russia remains high. Psychiatric education has, in fact, been a long tradition in Russia, since its introduction in the Imperial Medical-Surgical Academy in 1835. Now, education in psychiatry is offered in Medical Institutions. It consists of 1-2 years of postgraduate practice in mental hospitals, accompanied by specialized courses in various psychiatric departments. The essential strength of the system lies in the fact that nonclinical, basic science students are also available for and enthusiastic about involvement in psychiatric sciences. Today, in a rare trend of relative stability and economy improvement, at least some research institutions appear to be on their way to recovery, albeit without growth. For example, I have not heard, as indicated in the previous Guest Editorial about academic psychiatry in Israel, ${ }^{1}$ that someone returned from abroad to get appointed to a prestigious position in academic psychiatry. For those who stay in Russia, there are a host of problems to be dealt with. Providing living conditions for postgraduate students in a very expensive megalopolis (as Moscow is now) is a constant challenge for their mentors. Finally, construction of new laboratory infrastructure with costly state-of-the-art equipment is clearly a key requirement in basic psychiatric research. Under these circumstances, international cooperation (particularly in areas where one can manage to be in a competitive position) remains vital to achieving research excellence in Russia. The development of technology-intensive programs, such as those in pharmacogenomic, proteomic and metabolic research, is a current necessity that must be prioritized in academic psychiatric research in Russia. On one occasion, in one lab, the glass shelves have been returned to the cupboard-the new ABI Analyzer eventually arrived.

E Rogaev ${ }^{1,2}$

${ }^{1}$ Brudnick Neuropsychiatric Research Institute, University of Massachusetts Medical School, USA; ${ }^{2}$ Laboratory of Molecular Brain Genetics, Research Center of Mental Health, Academy of Medical Sciences, Zagorodnoe sh 2/2, Moscow State Lomonosov University, Moscow 113152, Russia E-mail: Evgeny.Rogaev@umassmed.edu

1 Shalev A. Mol Psychiatry 2004; 9: 639-640. 